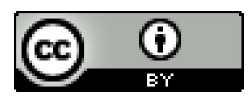

Esta obra está sob o direito de Licença Creative Commons Atribuição 4.0 Internacional.

\title{
DIFICULDADES DE APRENDIZAGEM NA LINGUAGEM ESCRITA
}

\author{
Fernanda Guerra Melo da Silva
}

\section{RESUMO}

Este artigo é um recorte da dissertação de mestrado que tratou das metodologias da linguagem escrita nos anos iniciais do ensino fundamental na rede municipal de Recife /PE. O mesmo, tem por objetivo esclarecer sobre as diversas dificuldades, que as crianças em fase de alfabetização, encontram na linguagem escrita, identificando assim as implicações que acontecem nesse processo. A pesquisa de campo foi realizada em cinco escolas municipais da cidade de Recife, após autorização de seus diretores, em consonância com o comitê de ética, com professores dos anos iniciais do ensino fundamental, juntamente com os protocolos de análise da escrita dos estudantes. O estudo realizado aponta uma forte influência tradicional do ensinar a escrever, através de formas prontas para a memorização. Precisaria haver mudanças significativas na sala de aula de acordo com as necessidades dos alunos, explorando mais outros tipos de materiais didáticos. $\mathrm{O}$ que podemos concluir é que a linguagem escrita precisa de uma estratégia específica, pois se trata de um processo individual cognitivo e motor, em que no início precisa do auxílio de um escriba. Desse modo, é proposto a continuação do estudo em relação a metodologia aplicada pelos professores em sala de aula, já que a escrita é um processo muito complexo.

Palavras-chave: Dificuldades. Linguagem escrita. Ensino Fundamental.

Submetido em dezembro de 2019 e aceito em janeiro de 2020.

\footnotetext{
1 Possui graduação em Pedagogia pela Faculdade de Ciências Humanas de Olinda (1996), é especialista em Coordenação Pedagógica e Supervisão Escolar (2001), Mestra em Ciências da Educação, pela Universidade Americana-PY (2015).
} 


\section{INTRODUÇÃO}

A partir de muitas observações realizadas de alunos que terminam os anos iniciais do Ensino Fundamental com a leitura e escrita ainda muito rústica, surgiu a inquietação e o desejo de investigar as metodologias utilizadas pelos professores da rede municipal de ensino de Recife sobre a língua escrita que vem sendo utilizada nas escolas e a compreensão que os mesmos tem sobre esse tipo de linguagem.

A linguagem escrita está presente na vida dessas crianças e jovens que entram em contato com blogs, e-mails, receitas, outdoor, jornais, revistas, livros, propagandas nos muros e outros tipos, porém não conhecem a sua funcionalidade e nem a sua história.

Nas escolas o que mais se pratica é a linguagem oral. Muitos professores e professoras encontram dificuldades de acompanhar o processo da linguagem escrita, muitas vezes pela quantidade de alunos em sala ou mesmo por acreditarem que a dificuldade de escrever esteja na criança.

A compreensão que a linguagem escrita é um código, vem sendo utilizada

\section{METODOLOGIA}

A pesquisa de campo foi realizada em cinco escolas municipais da cidade de nas escolas até os dias atuais. As crianças quando escrevem o que falam, escrevem ortograficamente incorretos e sofrem consequências gravíssimas como o fracasso e a exclusão.

Pergunta-se: será que todas crianças que não alcançam êxito na linguagem escrita apresentam algum distúrbio de aprendizagem?

A escrita muitas vezes começa a se desenvolver na Educação Infantil e quando iniciam o Ensino Fundamental começam a se aprisionar em cópias e na perfeição das letras. Fazendo com que as crianças parem de representar a escrita do jeito que pensam. Tornam-se meros reprodutores de uma ideologia dominante. Contribuindo para elevar o índice de analfabetismo funcional, onde a língua é aprendida e não compreendida.

$\mathrm{O}$ artigo tem por finalidade analisar as estratégias metodológicas utilizadas pelos professores nos anos iniciais do ensino fundamental, identificando assim as implicações que acontecem nesse processo. Trazendo como contribuição o estudo e a reflexão por parte dos professores sobre o processo da escrita.

Recife, após autorização de seus diretores, em consonância com o comitê de ética, com professores dos anos iniciais do ensino 
fundamental, juntamente com os protocolos de análise da escrita dos estudantes.

Utilizou-se na parte teórica alguns autores como Zorzi (2003), Sanchez (2004), Morais (2006) e Cunha (2011).

Dentro da educação escolar encontram-se muitas particularidades em relação ao processo de aprendizagem, no que diz respeito ao desenvolvimento da linguagem. Pode ser diferenças individuais, transtornos ou até mesmo patologias. A heterogeneidade que acontece nesse processo é muito grande e precisamos estar atentos para não julgarmos ou tratarmos de forma diferente.

Os dados coletados no questionário aplicado a vinte e cinco (25) professores das séries iniciais do Ensino Fundamental, efetivos, do Município de Recife-PE, contemplaram cinco questões que procura conhecer as metodologias que são aplicadas

\section{RESULTADOS E DISCUSSÕES}

Muitos professores não conseguiram identificar o método que é utilizado em sala de aula, outros tiveram dúvidas a respeito dos nomes dos métodos e outros compreendem a necessidade de trabalhar de forma que se analise o todo e depois parte-se para as unidades menores que no caso é o analítico-sintético. Alguns trabalham com o sintético e assume o tradicionalismo, acreditando que dessa no ensino da linguagem e quatro questões que se referem à expressão escrita dos alunos nas séries iniciais do Ensino Fundamental.

Foram realizadas observações em sala de aula, nas turmas de $1^{\circ}$ ao $5^{\circ}$ dos anos iniciais, sem a intervenção do pesquisador.

As produções textuais dos estudantes, foram recolhidas e analisadas de acordo com o planejamento diário do professor.

Parafraseando Sampiere (2008). Os dados coletados nos ligam ao mundo empírico e quando sistematicamente coletados fornecem base para a produção intelectual. A coleta de dados é o ato de pesquisar e de procurar informações sobre o tema escolhido facilitando assim, uma posterior análise, ponto a ponto dos fatos e do fenômeno que estará sendo investigado.

forma o aluno aprende a escrever, outros avançaram na forma da análise e trabalham com um método mais global que é o de análise de textos e palavras.

$\mathrm{Na}$ expressão escrita dos alunos a maioria dos professores afirmou que apenas $20 \%$ dos seus alunos produzem um texto e que sentem muita dificuldade nesta atividade. Outros falam que os que não apresentam dificuldades de aprendizagem conseguem produzir um texto de acordo 
com a sua série e outros falaram que a turma consegue escrever textos, pois já sabem ler.

A maioria dos professores disse que às vezes, pois, sempre a produção do texto resulta de uma atividade lúdica e que os alunos precisam ser bastante estimulados para poder escrever. Outros falaram que os alunos não escrevem por que sentem preguiça e pela falta de criatividade. Os que falaram que sim disseram que os alunos que gostam de escrever, são os que já sabem ler.

As observações de campo foram realizadas de forma não participativa por cinco (5) dias em cada escola.na escola 1 percebe-se pouco incentivo para linguagem escrita, dando-se mais ênfase a leitura. O material escrito exposto na escola eram letras, silabas e palavras isoladas. Pouquíssima produção textual dos alunos. No planejamento dos professores a linguagem escrita aparece como um complemento da linguagem oral. No projeto político pedagógico observasse um grande incentivo à leitura através de projetos didáticos. A maioria dos alunos na hora de escrever um texto se sentiu incomodados e pediam para que os professores colocassem no quadro as palavras ou que ajudassem a escrever e se recusaram a fazer a atividade. Outras crianças perguntaram se valeria nota e por que iriam fazer esse tipo de atividade. Duas professoras do ano 1 quando avisadas da solicitação da produção de texto se assustaram e alegaram que as crianças não sabiam ler. E pediram para que fosse realizado um ditado de palavras com os padrões silábicos trabalhados. Em uma das turmas a professora trabalhava um bingo e colocava como pesquisa um silabário. Percebe-se que o método aplicado pelos professores é o sintético, dando ênfase ao método silábico, priorizando a leitura e cópia das palavras. A produção escrita pouco aparece no dia-a-dia. Os livros didáticos apresentam um nível elevado para os estudantes alegam alguns professores pois são livros para alunos que já sabem ler.

$\mathrm{Na}$ escola 2, observa-se pouca produção escrita dos alunos, material escrito pela escola muito pouco. Observa-se o uso do método sintético das partes para o todo. Priorizam muito a leitura. O projeto político pedagógico apresenta atividades que contemplam projetos didáticos que envolvem leitura e escrita. A proposta pedagógica da escola propõe uma meta de elevar em $90 \%$ a leitura e a escrita dos alunos. Os livros didáticos apresentam vários gêneros textuais que incentivam a escrita, porém os professores alegam desinteresse dos alunos para esse conteúdo. Faltam livros e os que têm livros deixam em casa e ficam atrapalhando a aula. Muita indisciplina em sala de aula, muita atividade no quadro para conter os alunos.

$\mathrm{Na}$ escola 3, a pedagogia de projetos é muito presente. Percebem-se, algumas atividades coletivas dentro de suas 
especificidades e turmas de acordo com temas propostos. A linguagem escrita é mais divulgada dentro das salas de aula, porém a ênfase maior no trabalho está na leitura. Os métodos utilizados na maioria das vezes é o sintético analítico. E que muitos professores tiveram dúvidas sobre o tipo de método utilizado em sala de aula. $\mathrm{O}$ projeto político pedagógico apresenta em uma de suas ações elevarem o índice de leitura nas séries iniciais do ensino fundamental, trazendo como atividade sala de leitura para os alunos com dificuldades de leitura. Os livros didáticos são bem utilizados, porém pouco se explora a produção escrita. A linguagem escrita é utilizada como cópia de textos. Muitos alunos apresentam dificuldades de aprendizagem na leitura e na escrita e o professor fica com uma sobrecarga grande em sala de aula, mas consegue através dos projetos obterem êxito.

Escola 4 - Os professores apresentaram muita disponibilidade para ajudar na pesquisa. Demonstraram algumas técnicas para desenvolver a linguagem escrita como jogos de sílabas, bingo de letras, jogo de trilhas com palavras. A turma do $5^{\circ}$ ano trabalhava em grupo com uma paródia. Porém percebe-se pouco incentivo a linguagem escrita a ênfase maior está na leitura. O projeto pedagógico aponta proposta de trabalhar com vários gêneros textuais e isto ficou bem visto em algumas salas. A dificuldade maior de escrever aparece mais nas turmas de $1^{\circ}$ ao $3^{\circ}$ anos e os alunos quando solicitados a escrever diziam "pede a tia ela já sabe escrever" "eu sei escrever bem pouco". Nas turmas de alfabetização o método que predominava era o sintético como o silábico e o fonético, nas turmas de $4^{\circ}$ e $5^{\circ}$ ano já se trabalhavam com um método mais global.

Escola 5- Poucas produções dos alunos na escola, as produções estavam contempladas na sala de aula. Os professores têm algumas dificuldades pela infraestrutura da escola e falta de apoio da família. Trabalham com jogos de alfabetização e com projetos didáticos que contemplam a linguagem escrita. No projeto político pedagógico não aparece nenhuma ação que contemple leitura e escrita, apenas reforço para as áreas de matemática e de língua portuguesa sem especificar conteúdo. No planejamento dos professores percebem-se competências que desenvolvem a linguagem escrita, sem está atrelada a linguagem oral aparece como dois processos.

A partir da pesquisa realizada nessas escolas observa-se certa inquietação do professor sobre esse tipo de linguagem tão estigmatizada que para escrever tem que ler. O processo caminha junto, como diz Emília Ferreiro. E a percepção é que a prioridade maior dos professores é que os alunos leiam, a escrita vem como consequência. 
Essa seria a compreensão dos mesmos sobre esse outro tipo de linguagem, os métodos aplicados sempre dão ênfase a leitura, a escrita pouco é estimulada através dos métodos. As técnicas e as estratégias para a língua escrita são pouco exploradas pelos professores e quando acontece não tem uma conclusão do que se começou. Recebem apoio pedagógico na medida em que produzem e quando sentem necessidade. A linguagem escrita está tão presente na sociedade, porém, ainda precisa fazer mais parte do cotidiano das escolas.

Outro ponto observado na pesquisa foram os projetos didáticos trabalhados nas escolas, ao qual se propõem uma sequência didática de atividades mais podendo contemplar assim a linguagem escrita. Porém, o foco maior que encontramos foi na leitura.

$\mathrm{Na}$ medida, que acontecia às intervenções de sugestões para o trabalho com esse tipo de linguagem percebe-se a ebulição de ideias e de criatividade muitas

\section{CONCLUSÃO}

Numa nova perspectiva de ensino da linguagem escrita faz-se necessário uma análise e reflexão sobre o que se vai escrever e sobre o que se escreve. Alguns autores propõe uma reinvenção nas estratégias didáticas sistemáticas no que diz respeito a língua. vezes adormecida pelo professor por vários fatores e um deles é a rotina e a falta de condições de trabalho. E assim, ainda conseguem desenvolver um bom trabalho em sala de aula.

O método utilizado pelos professores sempre parte das unidades para o todo, alguns podem até iniciar com um método mais global. Porém, volta sempre para a mecanização das palavras e letras. A maioria, como se observa nos resultados utilizam o método silábico. Tradicionalmente a aprendizagem da escrita tem-se considerado como uma aprendizagem de um código de transcrição, do som para grafia.

Diante de todo o histórico vivenciado pela linguagem escrita, percebese a forte influência tradicional do ensinar a escrever, através de formas prontas para a memorização. O método silábico parte de uma visão simplista que justifica a solução do ler e escrever através da transmissão e da correspondência do som e da grafia.

A linguagem escrita na escola resume-se em produção textual narrativa. A realização de atividades no dia-a-dia como interpretar e produzir uma tabela, um gráfico, escrever uma mensagem para o outro, comparar mercadorias umas às outras, fazer uma simples lista de compras ou de coisas que lhes agradam pouco está 
sendo desenvolvidas na escola. Percebe-se uma distância da linguagem escrita que circula na sociedade e a que é desenvolvida na escola.

Observa-se que as implicações estabelecidas pelos professores investigados em relação à linguagem escrita é que o aluno precisa aprender a ler primeiro para depois desenvolver a habilidade de escrever. Verifica-se na teoria e na prática que os métodos expostos não se percebem a intenção de promover a escrita em sua função social e que a escrita inicial aparece de forma mecânica.

As estratégias e técnicas aprendidas nas formações continuada, quando acontece, precisam ser adaptadas à realidade da sala de aula dos professores. Muitas vezes pelo nível de aprendizagem dos alunos e muitas vezes pela falta de material didático adequado. Muitos dos professores recebem o material da escola como jogos, tabelas, agendas, mas sentem dificuldades em aplicá-los em sala de aula, pelo número de alunos em sala e pela falta de prática com o novo material.

Os alunos precisam pensar para escrever, precisam entender o que é a escrita e para que ela serve. Os alunos precisam diferenciar o que vão ler do que vão escrever, precisam fazer com autonomia mesmo que o resultado não seja da forma convencional. É preciso entender a função social da escrita.
Observa-se interferências de fatores externos a pesquisa como: falta dos professores, grande quantidade de alunos em sala de aula, a indisciplina dos alunos, a falta de estímulo do professor e do aluno e a falta de tempo da gestão.

Precisa-se de estratégias mais específicas que complementem essas outras atividades para que haja uma reflexão da lingua escrita como: planejar o texto, redigir rascunhos e revisar.

Muitos professores alegam que os alunos não escrevem por falta de criatividade e que os mesmos não conseguem organizar as ideias. A pesquisa nos aponta que os alunos conseguem expressar o que pensa um pouco limitado, mais expressam. O que se faz necessário é o incentivo para revisar e refletir sobre a lingua colocando-se propósito no que se escreve e socializando as produções.

Encontramos nas salas de aula vários rítmos de aprendizagem, várias formas de aprender e quando não se utiliza estratégias que sejam adequadas para cada tipo de ensino, poderá comprometer a aprendizagem e até mesmo levar ao desestimulo por ambos os sujeitos envolvidos neste processo, professor e aluno.

Compreende-se que a influência de fatores sociais são presentes nas salas de aula e que é de suma importância explorar no processo de ensino as experiências dos 
alunos para que essa experiência se transforme em uma aprendizagem significativa.

A metodologia da linguagem escrita deverá ser específica para cada ano/série do Ensino Fundamental, pois cada etapa de ensino dar mais ênfase há algumas atividades pelo amadurecimento do desenvolvimento da criança, exemplificando no $1^{\circ}$ ano do Ensino Fundamental percebe-se a necessidade do domínio do sistema de escrita alfabética, onde a criança vai compreender como funciona a escrita convencional na nossa sociedade. No $2^{\circ}$ ano estabelece-se uma relação grafo fônica das palavras (grafemafonema) e $3^{\circ}$ ano trabalha-se para o domínio das normas ortográficas, $4^{\circ}$ e $5^{\circ}$ ano continua-se o trabalho para uma escrita de forma convencional onde se apresenta coesão e coerência no que se escreve.

E o que se observa nas análises das produções escritas dos alunos é que quando eles chegam ao $4^{\circ}$ e $5^{\circ}$ ano o desinteresse é maior em relação a uma produção com eficácia e de boa qualidade.

A linguagem escrita precisa em primeiro lugar ser compreendida pelo professor, saber qual a função e como ela será útil na vida do aluno. Investigando e experimentado métodos que estimulem essa linguagem, percebendo que ler e escrever são processos diferentes, mas indissociáveis e que cada processo tem seu tempo e suas atividades específicas. Dando-se ênfase para um trabalho que envolva a prática social desse tipo de linguagem.

A pesquisa teve como contribuição um estudo mais aprofundado sobre as metodologias da linguagem escrita. Verificou-se que todos os métodos utilizados pelos professores, precisam ter especificidade para esse tipo de linguagem. Pois, ela se apresenta como um objeto de conhecimento e não como uma decifração de códigos.

A linguagem escrita precisa ser vista como um processo independente da linguagem oral, que está interligado, mas que precisa de uma metodologia própria.

$\mathrm{Na}$ busca de mais respostas para o problema constatou-se a necessidade de investimento em estratégias próprias para a escrita como: planejar, redigir e revisar o que se escreve.

Percebe-se a necessidade do professor em conhecer cada método para a linguagem escrita que ele aplica em sala de aula, pois passa despercebida essa especificidade da língua.

Cabe enfatizar que a escola precisa se mobilizar e realizar formações especifica nas áreas que os professores apresentam dificuldade de trabalhar. Pois, neste contexto verificou-se que grande parte dos professores precisa de apoio pedagógico e de formação continuada na escola. 


\section{REFERÊNCIAS}

CUNHA, Eugênio. Práticas pedagógicas para inclusão e diversidade. RJ: Editora Wak, 2011.

GÓMEZ, Ana Maria Salgado.

Dificuldades de aprendizagem. RJ: cultural, 2011.

MORAIS, Antônio Manuel Pamplona. Distúrbios de aprendizagem. SP: Editora Edicon, 2006.

MORINO, Carlos Richard Ibañez. La etapa escolar de los 6 a los 12 años. Buenos Aires: Universidad Católica Argentina, 2008.
RISUEÑO, Alícia. Transtornos específicos da aprendizagem. Buenos Aires: Editorial Bonum ,2005.

SANCHEZ, Garcia. Dificuldades de aprendizagem e intervenção psicopedagógica. Porto Alegre: Artmed, 2004.

SANTOS, Mônica Alves Ferreira. Dificuldades de aprendizagem na alfabetização dos alunos de classes populares. Universidade Candido MendesPós-graduação "latu sensu”, Monografia. Rio de Janeiro,2004.

ZORZI, Luiz Jaime. Aprendizagem e distúrbios da escrita. Porto Alegre: Artmed, 2003. 